\title{
TRADICIONES Y TRANSICIONES EN LAS ORGANIZACIONES PRODUCTIVAS DEL MÉXICO MESTIZO. DOLORES HIDALGO, GUANAJUATO
}

\author{
TRADITIONS AND TRANSITIONS IN THE PRODUCTIVE ORGANIZATIONS \\ OF MEXICO MESTIZO. DOLORES HIDALGO, GUANAJUATO
}

\author{
Manola Sepúlveda Garza*
}

\begin{abstract}
En este artículo se trata la tradición ranchera en el municipio de Dolores Hidalgo, Guanajuato, México. Se analiza por qué los movimientos sociales de las primeras décadas del siglo XX no lograron destruir la base del trabajo en aparcería en el que se edificaba la producción agroganadera de la hacienda de antaño y, contrariamente, este tipo de organización se afianzó tanto en las fincas privadas como en los ejidos. Asimismo, en el presente texto se discuten los elementos tradicionales y transicionales de la sociedad dolorense caracterizada por un sistema jerárquico y masculinizado, donde las redes de parentesco y el catolicismo tuvieron (y tienen) gran importancia. Todo esto en un contexto en el que, opuesto a todo proyecto y legalidad, se intensificaron las relaciones mercantiles en los ejidos.
\end{abstract}

Palabras claves: Hacienda, aparcería, tradición ranchera, ejido, cambio social.

This article analizes the ranchera tradition in the municipality of Dolores Hidalgo, Guanajuato, Mexico. It discusses why social movements of the early twentieth century not only failed to undermine the basis of the sharecropping in which the old mixed agricultural and livestock production system was built, but rather strengthen this type of organization both in private farms and ejidos. This text also discuses traditional and transitional elements in Dolorense society, characterized by a masculine hierarchical system where kinship networks and Catholicism had (and still have) great importance. All this is the context in which market relations in the ejidos were intensified, contrary to the policies and laws of the new land tenure system.

Key words: Private farms, sharecropping, ranchera tradition, ejido, social change.

\section{Introducción}

Los estudios económicos, políticos y culturales de los campesinos constituyen una temática central en la antropología de América Latina por el papel que estos han desempeñado en diversos movimientos sociales y en la organización política de los Estados del siglo XX. En su tratamiento no ha habido convergencias teóricas, quizá porque al grupo al que se refieren es heterogéneo y un sector ha tenido cambios importantes que van al parejo con el desarrollo del capitalismo.

En efecto, en el campo mexicano existen matices diferentes en los "puntos de partida" de sus organizaciones: no fue lo mismo las pautas organizativas que dictó la Corona Española para las poblaciones indígenas del sur del país, que para las poblaciones del centro y del norte que estuvieron inmersas en procesos de colonización de vastas extensiones territoriales o en las explotaciones mineras. Si en el sur se establecieron haciendas al lado de las "repúblicas de indios" y ambas fueron unidades relativamente independientes, en el norte este fenómeno se presentó en menor escala, y más bien se obligó a los grupos indígenas (aliados o sometidos) a acompañar al español en el avance de la colonización, donde constituyó una verdadera empresa caudillezca (Cfr. De la Peña, 1993:152), con la que se implantó un modelo productivo y social específico que dio lugar a la organización hacendaria durante los siglos XVI y XVII. Por otra parte, tanto en el norte como en el sur la conquista y colonización estuvieron acompañadas por diferentes misioneros católicos, y ellos influyeron en la población nativa en la forma de ver al mundo. En breve, fue en esos tiempos que se impusieron ciertas formas organizativas en la población que con los años conformaron matrices culturales (con cierto sincretismo con elementos prehispánicos) cuyos rasgos no han desaparecido en la población del campo mexicano.

Según Redfield y Villarojas (De la Peña, 1993:136), hasta mediados del siglo XX en amplias

* Escuela Nacional de Antropología e Historia, México. Correo electrónico: manolasepulveda@yahoo.com.mx 
regiones del país (indígenas y algunos de los llamados pueblos originarios) persistían poblaciones que hablaban su lengua nativa y donde la mayoría no conocía el español; una organización comunitaria como principio de identidad; acceso a la tierra como patrimonio compartido; división del trabajo familiar y participación de sus integrantes en tareas comunitarias; una compleja organización ceremonial e instituciones comunales de gobierno. Se vinculaban con el gobierno estatal o federal por la escuela primaria y de la organización municipal, ejidal o comunal (De la Peña, 1993:138). Muchas de estas características persisten hoy, y para algunos es en este tipo de poblaciones donde habría que profundizar en el estudio de la organización social tradicional, quizá porque este modelo ha demostrado mayor solidez.

Sin embargo, en México y en América Latina existen otras tradiciones culturales que también han sido exploradas por los antropólogos. Aquí me referiré a aquellas que se desprenden de la organización de la hacienda que nació ligada al clero católico con un sello patriarcal y jerárquico. Esta unidad productiva, que perduró hasta mediados del siglo XX y en algunas regiones del país persiste hasta hoy, fue vista por algunos como una unidad típica del feudalismo y, por otros, como una célula del capitalismo atrasado. En mi opinión, en la hacienda porfiriana del norte de Guanajuato las relaciones del patrón con los trabajadores tenían elementos de explotación semifeudal: las familias campesinas residían en el territorio de la finca, tenían poca movilidad, su trabajo era pagado parte en dinero y parte en especie, y daban el diezmo al clero; pero las relaciones que los finqueros establecían hacia el exterior eran (y habían sido) de tipo mercantil: a finales del siglo XIX las ventas de sus productos fueron estimuladas por la presencia del ferrocarril.

En este trabajo el punto de arranque es la organización social y productiva en un municipio que tuvo como eje dominante a las haciendas agroganaderas. Parto de 1900 (porfiriato) y pretendo apuntar las etapas más sobresalientes que vivió la sociedad dolorense hasta 1960, es decir, hasta después de que se realizó la primera etapa del reparto agrario. Las políticas agrarias del Estado y los movimientos sociales propiamente dichos apenas los señalaré, para dejar mayor espacio a la descripción de las características económicas y sociales del municipio, y analizar las formas de organización productiva surgidas del reparto agrario (Mapa 1).
Según mi información, en Dolores Hidalgo la hacienda y el diezmo persistieron hasta los años setenta del siglo pasado. Se transformaron tanto por la modernización técnica productiva y el cambio de cultivos como por las políticas del Estado que favorecieron la formación de ejidos. En efecto, la aparcería tradicional fue substituida por el trabajo asalariado y con esto se derrumbó no solo una forma de producir, sino también un pacto social que, sin embargo, en poco tiempo reapareció parcialmente en la empresa agrícola como una forma de compensar el salario.

Es decir, el trabajo "a partido"1 como la base con que se edificaba la estructura de explotación de los recursos de la hacienda (surgido en la época colonial y minimizado durante el porfiriato) fue reactivado a pesar del reparto agrario cardenista y, lo que es más, en los años de 1940-1960 fue parte fundamental de la organización de la finca privada y del sistema ejidal. Y si en los ejidos se reprodujo la aparcería ${ }^{2}$, también lo hizo quien se quedaba con parte del producto del trabajador de campo que, en aquellos años, frecuentemente era el presidente del Comisariado Ejidal, el ejidatario poseedor de la tierra, o el exdueño de las tierras afectadas.

En efecto, contrario a lo que se pudiera pensar, el reparto agrario no siempre estimuló una distribución equitativa y democrática de los recursos para que el trabajador del campo se convirtiera en un productor "libre", dueño del producto de su trabajo y, en esta condición, relacionarse con el mercado y el Estado; su trabajo estuvo ligado a otros agentes que se apropiaban de parte de su producción, ya fueran las autoridades del ejido o los intermediarios comerciales. Por otro lado, al interior de los ejidos con mejores recursos (riego y/o cercanos a la cabecera municipal) se intensificaron los conflictos de poder y las relaciones mercantiles con la concentración de tierras, las ventas de los derechos ejidales, el manejo del crédito y el acaparamiento de las inversiones productivas del Estado.

El ejido de aquellos años representó una transición de formas y estilos de organización productiva que incorporó las estrategias de trabajo de la hacienda y que solo en la segunda parte del siglo XX logró cierta consolidación como célula de producción participativa ligada a los objetivos del Estado. En la actualidad, los ejidos viven una nueva transformación que, sin embargo, no niega sus raíces históricas y culturales. 


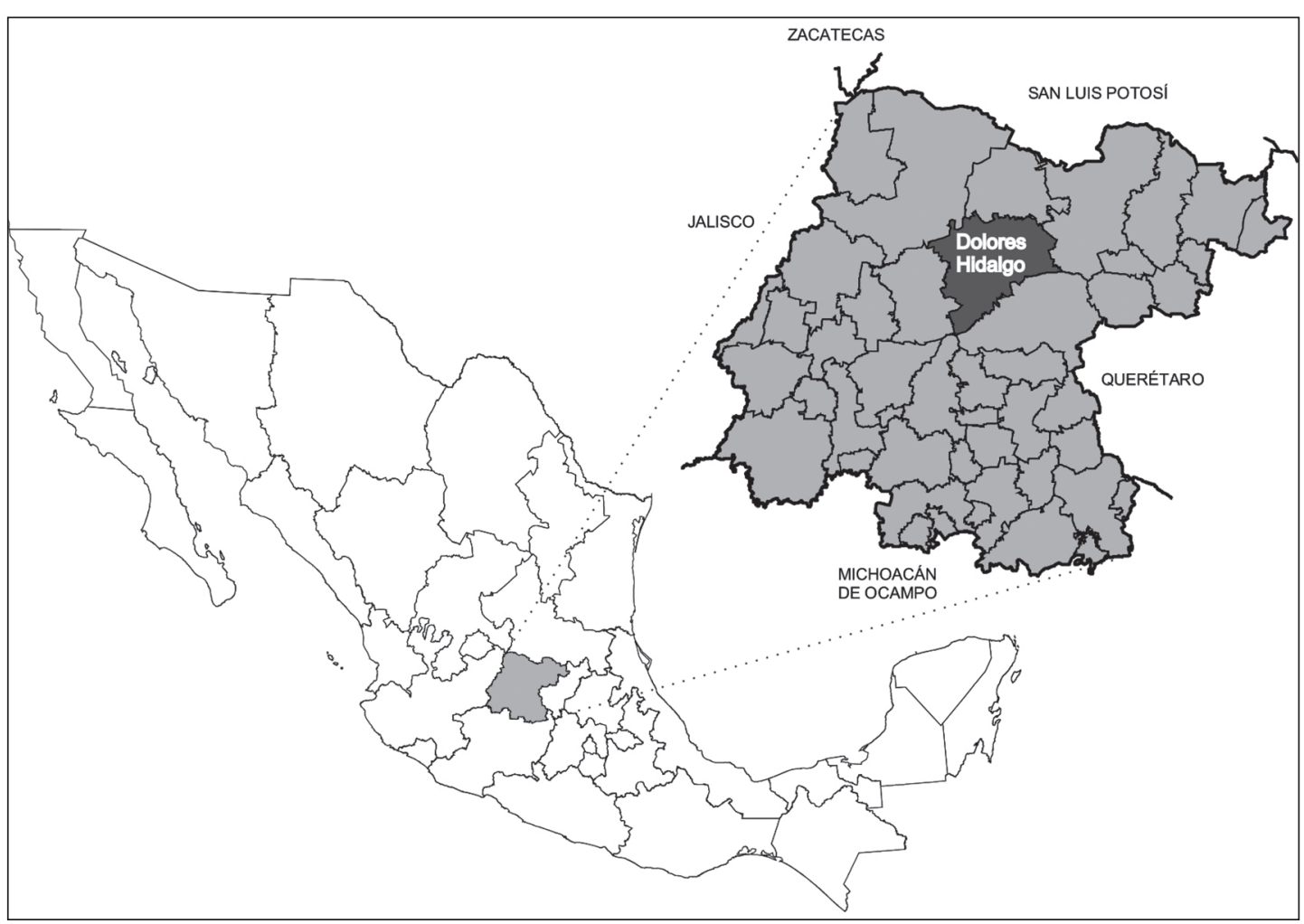

Mapa 1. México, Guanajuato y Dolores Hidalgo.

Fuente: Elaboración propia, basadas en el Instituto Nacional de Estadísticas, Geografía e Informática. Prontuario de información geográfica municipal de los EUM, Dolores Hidalgo, CIN, clave geoestadística 11014. México, 2009.

\section{El punto de partida: la sociedad dolorense en 1900}

El censo de 1900 nos muestra un municipio con 44.704 habitantes $(4,21 \%$ del total dela entidad) de los cuales $14,51 \%$ vivía en la cabecera municipal; $2,2 \%$ en la congregación de Joconoxtle El Grande y $83,17 \%$ en haciendas y ranchos. Se trataba de una población rural muy dispersa donde la mayoría $(72,4 \%)$ vivía en pequeñas rancherías de menos de 200 habitantes $^{3}$.

El censo señalaba a Joconoxtle El Grande como la única congregación, pero además existían (y existen) otras congregaciones como San Marcos de Arriba, San Marcos de Abajo, Joconoxtle, Las Rusias, Joconoxtlito, Joconoxtle de Rematado, San Damián, Santa Bárbara, San Pedro, San Vicente y Palacios, entre otros. ${ }^{4}$ Estos poblados están ubicados en el suroeste del municipio, en una zona poco apta para el cultivo, ahí parece haber existido un "corredor" de asentamientos cuyos pobladores eran de origen otomí. También Adjuntas del Río y El Llanito, cerca de la cabecera municipal, eran congregaciones $^{5}$ (Mapa 2).

La mayor parte de la población era hispanohablante. El censo registró 2,52\% de hablantes de otomí, residentes en El Llanito o en las otras congregaciones, identificadas como rancherías. Solo el 13,85\% sabía leer y escribir; el 4,60\% sabían leer y la enorme mayoría $(81,55 \%)$ era analfabeta. ${ }^{6}$ En cuanto a la religión, el 99,9\% se declararon católicos y el $0,1 \%$ se dijo protestante. Se registraron 115 templos católicos que se ubicaban en la cabecera municipal, en la parte central de las haciendas y en los poblados de mayor número de habitantes ${ }^{7}$.

En Dolores se inauguró la línea del ferrocarril en la ruta México-Laredo en 1888. La cabecera municipal también estaba comunicada con "caminos reales" a la capital de la entidad, a San Miguel de Allende y a otros municipios aledaños. 


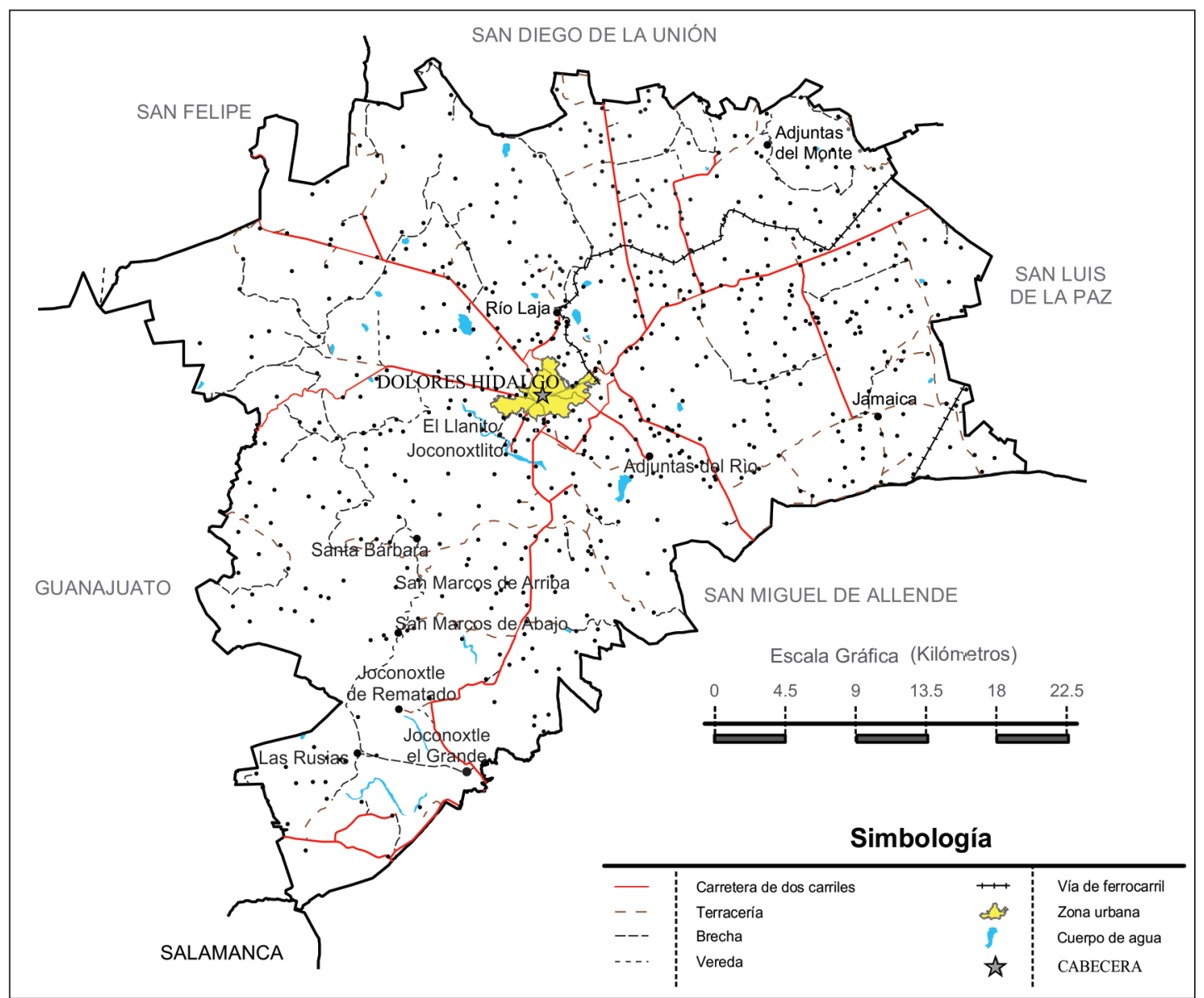

Mapa 1. Municipio Dolores Hidalgo, Guanajuato.

Fuente: Elaboración propia, basadas en el Instituto Nacional de Estadísticas, Geografía e Informática, Prontuario de información geográfica municipal de los EUM, Dolores Hidalgo, CIN, clave geoestadística 11014. México, 2009.

En lo que se refiere a la ocupación y al empleo, el censo registró alrededor del $80 \%$ como peones de campo; $2,70 \%$ agricultores; $6,9 \%$ artesanos; $4,95 \%$ en otros empleos (mineros, sirvientes); $5,8 \%$ profesionistas, empleados públicos o comerciantes ${ }^{8}$. Es decir, alrededor del $17 \%$ de la población no tenía una relación directa con la tierra, ni con los trabajos de las haciendas. Lo "amplio" de este sector, posiblemente tiene que ver con la incorporación de gente de las congregaciones que perdió sus tierras de cultivo en la segunda parte del siglo XIX.

Las haciendas y medianas propiedades eran las unidades agrícolas y ganaderas en torno a las cuales giraban las otras actividades del municipio. Había fincas cuyas extensas superficies eran montañosas con pocas superficies planas y sus actividades se centraban más en la explotación del ganado mayor (Trancas, por ejemplo) y otras que se ubicaban en superficies planas, con riego, donde también había ganado, pero donde era más factible la producción de granos (El Gallinero, por ejemplo). En ambos casos la producción fundamental era la ganadería extensiva y el cultivo del maíz, frecuentemente intercalado con el frijol. En menor escala también se producía trigo, frutales, maguey y nopales; de los agostaderos se obtenía carbón, leña, pastos, cantera y una gran variedad de frutos silvestres. La riqueza y el éxito de una finca residían, en buena parte, en la gran variedad de sus recursos y en su explotación, lo cual fue una forma de atenuar el impacto de una economía inestable a consecuencia del clima y las fluctuaciones en la producción. 
El centro de las fincas más antiguas lo integraban la casa del hacendado, la parroquia, norias y estanques de agua, huertas de árboles frutales, graneros, tienda de raya, establos y, en algunos casos, una plaza para practicar "toros" y jaripeos. A poca distancia se ubicaba el asentamiento de los trabajadores. Este modelo arquitectónico fue heredado de la época colonial y recreado por los propietarios de los siglos XIX y principios del XX.

En las fincas más importantes sus amplias superficies solían dividirse en sectores bien diferenciados: había un sector de tierras de riego que eran trabajadas por un mayordomo con la ayuda de peones. En ellas se cultivaba trigo, cebada, frijol y en menor escala ajo, camote y jitomate.

Había otros sectores de tierras conocidas como de temporal de "primera" o de "segunda" . En ellas se producía maíz, frijol, nopal y maguey. Se trabajaba con peones, pero, también, podían cederse parte de esas tierras a algunos de los trabajadores como una forma de completar el salario. Las superficies de menor calidad o que estaban enmontadas se les daba a trabajar a los aparceros a quienes se les conocía como "medieros" o "tercieros". En el primer caso, el patrón aportaba la tierra y la semilla para sembrar, y el mediero ponía su trabajo y la yunta jalada por bueyes; y en el segundo, el terciero solo colocaba su trabajo. El producto obtenido se repartía entre el patrón y el mediero (50\% de la cosecha) o el terciero $(33,3 \%)$ y los esquilmos eran usados para la alimentación del ganado del dueño de la finca. Aunque cada finca tenía sus particularidades, los diferentes relatos coinciden con lo que dice Antonio Vargas que le contaba su padre: “...los acasillados eran los más cercanos al patrón. Tenían todos los beneficios y más ventajas que los medieros o tercieros... estos ocupaban el último lugar en la finca y se encargaban de las tareas más duras..."10.

Otro sector lo representaban tierras de cultivo que estaban en "descanso". Se trabajaba con yuntas jaladas por bueyes y con el sistema de "año en vez", es decir, las tierras se dejaban sin sembrar un año. También había tierras que eran utilizadas para potreros y para el pastoreo libre del ganado, y existían las superficies no aptas para el cultivo de donde se obtenía gran variedad de frutos silvestres y otros productos como leña, carbón, madera, piedra y se practicaba la cacería ${ }^{11}$.

Junto a la distinción de las tierras por su calidad y utilización, existía una división jerárquica de trabajadores: en el centro un administrador, quien era apoyado por un rayador (pagador) y por capataces para manejar las "cuadrillas" integradas por 8 o 10 peones. Para cuidar el ganado vacuno había caporales, que se apoyaban en el trabajo de los vaqueros y ordeñadores, y para el ganado lanar y caprino había "vacieros" que se auxiliaban de los pastores. Los encargados del ganado frecuentemente vivían cerca de los potreros o en el caserío aledaño al casco de la finca, eran trabajadores con mejor estatus que el peón y este último tenía mejor posición que el aparcero ${ }^{12}$. En fin, los trabajadores estaban diferenciados en función de sus actividades y según la confianza que les tenían sus patrones. Esto se reflejaba en la cercanía física de la habitación del trabajador y de su familia al casco de la hacienda.

La yunta jalada por bueyes era el instrumental básico para las labores productivas. Pero además, "una yunta" definía una relación de trabajo (patrónpeón, patrón-mediero); la superficie sembrada podía ser de 5 a 6 ha, según la calidad de las tierras y, en algunos casos, el salario. En efecto, los trabajadores acasillados recibían una parte del salario en especie: en La Venta, por ejemplo, un mayordomo obtenía su salario y el producto de la siembra de dos "yuntas" de maíz y frijol, cuyo consumo debía administrar durante el año; un vaquero, además de su salario, recibía el producto de una "yunta"; y un peón, además de su salario (37 centavos), doce cuarterones ${ }^{13}$ de maíz y dos de frijol a la semana, trabajando de 12 a 13 horas diarias ${ }^{14}$. También existían los trabajadores que residían fuera de la hacienda y que eran empleados durante las cosechas o para algunas labores específicas con un salario similar al de los peones.

El grupo de trabajadores acasillados era relativamente estable y no había gran movilidad: personas que alguna vez se habían dedicado a la minería se podían incorporar a las haciendas y esto era más fácil si contaba con el aval de parientes en el lugar, o si tenía cartas de recomendación; las familias de jóvenes podían trasladarse a otras haciendas, siempre y cuando no tuvieran deudas en la finca de origen y llevaran una recomendación o "permiso" de sus patrones ${ }^{15}$. La vivienda, el empleo y en sí la subsistencia del trabajador y de su familia dependía de la hacienda.

En los caseríos de las fincas debió tener mucha importancia las relaciones familiares. Todavía persiste una organización en la que el padre tiene una gran autoridad en la casa donde también viven los matrimonios de sus hijos hombres. La vivienda más 
antigua es la de los padres y, en el solar, se observan las construcciones de los hijos (hombres) que van formando nuevas familias. Así, se da la convivencia de tres generaciones por línea masculina: abuelos, hijos y nietos, y es frecuente la explotación en común de las tierras y la división del trabajo según género y grupo de edad.

La hacienda, en sus relaciones externas, estaba vinculada a un mercado, en parte como abastecedora de los centros mineros cercanos o de regiones más distantes gracias al ferrocarril. Además, hay que señalar el vínculo económico del trabajador con el clero: del producto de su trabajo, el $10 \%$ era para entregarlo a la Iglesia (diezmo), práctica que persistió a pesar de que formalmente fue anulada por las leyes Juaristas en la segunda parte del siglo XIX. Nos cuentan: “...el pago se hacía en la parroquia de Dolores..., en cada rancho había 'diezmeros' que se encargaban de recogerlo. Se pagaban 'primicias' en junio y en la cosecha se entregaba el diezmo"16.

Tanto los peones como los vaqueros y aparceros eran trabajadores pobres que vivían en los límites de la subsistencia. Las referencias al salario, al número de horas trabajadas, días de descanso y la protección del trabajo de niños y mujeres, que se expresaron como reivindicaciones sociales por los gobernadores de Guanajuato en los años de la Revolución, confirman esta situación ${ }^{17}$. Por otra parte, este tipo de reivindicaciones también dejan ver el reconocimiento de este sector como sujetos para la aplicación de las leyes de protección al trabajo, es decir, esta población era percibida más como jornaleros agrícolas que como campesinado. Sin embargo, en los años posteriores (1929-1940) el gobierno federal les ofreció una opción agrarista y la protección al trabajo quedó relegada.

\section{Movimientos sociales $\mathbf{y}$ reparto agrario de 1910 a 1940}

Dolores Hidalgo (y Guanajuato) no fue la “cuna de la Revolución", pero tampoco un simple "escenario" por su ubicación geográfica. La inestabilidad político-administrativa y la crisis económica impactaron a todos los sectores de Guanajuato (y seguramente del país) y se reflejó en la emigración, bajas en la producción, carestía de alimentos, incertidumbre y, sobre todo, en la emergencia de organizaciones sociales que entraron en serios desacuerdos con los revolucionarios que tomaron la dirección del Estado en las décadas siguientes.
El esbozo de los movimientos sociales sucedidos de 1910 a 1940 rebasa los límites de este trabajo. Sin embargo, hay que apuntar que la mayoría de los dolorenses participaron a favor de continuas rebeliones de corte tradicional y católico de la posrevolución: en defensa de De la Huerta (1923), en la Liga Nacional de Defensa de la Libertad Religiosa (a partir de 1925), con los cristeros (1926-1942), en los movimientos Legionarios y de La Base (19311934) y con los sinarquistas (1937-1970)(Sepúlveda, 2011). Es decir, los dolorenses formaron parte de la contrarrevolución que se desató en el centro-oeste del país en los tiempos más intensos de las reformas sociales dirigidas por el grupo que se afianzaba en el gobierno central.

Al lado de esta oposición organizada e ininterrumpida, extendida más allá de los límites del municipio, un sector minoritario de la sociedad local se sumó a los proyectos del gobierno desde 1923; en 1928 y 1929 tomó las armas para combatir a los cristeros y persistió armado en defensa de las políticas agraristas hasta después de los años cuarenta.

El reparto agrario se dio en ese contexto de contrarrevolución y de violencia en donde se enfrentaron los terratenientes, sus trabajadores y guardias blancas, en contra de los maestros federales, funcionarios del Departamento Agrario y agraristas que representaban al programa del gobierno y que también estaban armados. Fueron muy frecuentes los enfrentamientos y pérdidas humanas en ambos grupos.

El grupo de terratenientes, la gran mayoría sinarquistas ${ }^{18}$, se oponían a la tendencia "comunista" del gobierno y manejaban un proyecto alternativo: para algunos trabajadores (mayordomos, rayadores, por ejemplo) el aumento de salarios y para la gran mayoría (peones y aparceros) hacerles pequeños propietarios, libres del control del Estado (Cfr. Serrano, 1992: TI 204) y sin "arriesgar la gloria eterna". La forma de hacerse de la tierra era a partir de la compra, pagándola con una parte de la cosecha. Desde ese entonces se generalizó la aparcería en las fincas del municipio ${ }^{19}$.

No ser agrarista fue una decisión colectiva de ranchos y fincas completas encabezadas por el finquero o patrón; mientras que la decisión de ser agrarista fue individual (del jefe de la familia nuclear). En esta opción, el ejidatario se vinculaba al Estado a cambio de quebrantar (o hasta anular) no solo las relaciones clero-patrón-trabajador, sino también las relaciones vecinales y la unidad 
familiar de corte patriarcal. Los agraristas, que podían montar a caballo y manejar las armas, eran hombres de 30 a 40 años que podían lanzarse a una lucha a muerte, dejando a los padres y tomando solo a su esposa e hijos, estos últimos, a pesar de su corta edad (14 o 16 años), ya formaban parte de las defensas rurales. La quiebra de redes sociales, más allá de la familia nuclear, fue una condición que ayudó a los agraristas a tener mayor movilidad en su acción política y militar, pero los dejó aislados a la hora de organizar el ejido y ponerse a producir (Cfr. Sepúlveda, 2011:85).

Ser ejidatario era haber tomado partido por el gobierno, haber enfrentado a la sociedad local y conocer su lado más violento; fue por medio de ellos que se hizo presente el proyecto del Estado que chocaba con el tradicionalismo provincial guanajuatense que no aceptaba una modernidad distanciada de sus tradiciones. Los ejidatarios pasaron a formar parte de las Reservas del Ejército, de la Confederación Nacional Campesina, del nuevo Partido de la Revolución Mexicana y del propio Estado.

El resultado de esta "revolución agraria" como se llama a este movimiento en el municipio, fue una hacienda debilitada y amenazada por la sombra del agrarismo, y un reparto de tierras parcial e inconcluso, al que los trabajadores le dieron la espalda.

En efecto, para 1940 el balance era desalentador: jurídicamente se habían firmado 23 resoluciones presidenciales de dotación, dos de ampliación y cuatro ejidos estaban en posesión provisional; se afectó una superficie de 20.382 ha (13,5\% del municipio), $53 \%$ cultivable, y se benefició a 1.670 jefes de familia. Pero en la realidad solo 13 resoluciones presidenciales estaban ejecutadas y tres ejidos estaban en posesión provisional y el número de ejidatarios no llegaba a las dos centenas en todo el municipio ( $12 \%$ de los beneficiados). La mitad de las afectaciones eran poblados que seguían trabajando como antaño, con la obligación de pagar las contribuciones y otorgar el $25 \%$ de la producción a la Delegación Agraria por trabajar en superficie ejidal (Cfr. Sepúlveda, 2011:78-81).

\section{Panorama municipal en los años cincuenta}

Los años cuarenta y cincuenta, conocidos en la literatura agraria como de contrarreforma, en Dolores Hidalgo se manifestó con el freno del proceso de reparto de tierras; la expulsión de la mayoría de los agraristas del territorio municipal; otorgamiento de garantías a las fincas privadas, y se favoreció su delimitación en perjuicio de la superficie ejidal, asimismo, se trató "a cualquier precio" hacer producir la superficie ejidal. Además, en los ejidos se construyeron templos católicos como una forma de borrar las ligas con el anticlericalismo con el que se les identificaba; se desarmaron las defensas rurales y las que persistieron estuvieron vinculadas con la policía municipal. El resultado de todas estas acciones fue la reconstrucción de las haciendas en sus formas y estilos productivos, y la tergiversación de la idea del ejido.

Para 1950 el municipio de Dolores Hidalgo tenía 44.722 habitantes, lo que representa prácticamente la misma cifra que la registrada en 1900 (44.704). La cabecera municipal concentraba el 21\% (9.294) y el 79\% restante (35.428) vivía en las rancherías, congregaciones y ejidos. El analfabetismo era del $75 \%$; la base alimentaria de la población era el maíz y el frijol (86\%) y solo el $14 \%$ consumía trigo ${ }^{20}$.

Las actividades agrícolas y ganaderas realizadas en las haciendas y ranchos seguían siendo el eje económico del municipio: el 79,1\% de los dolorenses se ocupaban en este ramo; el 8,45\% en la industria; y casi el $10 \%$ entre comercio, transporte y servicios ${ }^{21}$.

El municipio tenía una superficie total de 151.486 ha. De estas, el censo registró 135.784 $(89,7 \%)$ en propiedad privada (1.907 predios) y 23 ejidos con 15.702 ha $(10,37 \%)$ integrados por 950 ejidatarios 22 .

Los movimientos sociales de las décadas anteriores lograron un acomodo social diferente al existente a principios de siglo: se excluyó parte de la antigua elite porfiriana, se afianzó el sector de propietarios (medianos) y el de los concentradores de títulos de propiedad (mediante maniobras jurídicas y la expedición de certificados de inafectabilidad), surgió el sector de ejidatarios y aumentó la población urbana con una diversidad de empleos e independencia relativa de las haciendas, pero, a pesar de estos cambios, en el campo no hubo transformaciones productivas ni tecnológicas de fondo.

En efecto, en la superficie cultivable (37\% del territorio municipal: 55,704 ha.) la producción seguía siendo de maíz intercalado con frijol, maíz y frijol sembrados por separado, trigo, chile, jitomate, jícama, haba, lenteja, agave, tuna, nopal, y fruta ${ }^{23}$. El instrumental técnico era el mismo: arados de madera jalados con bueyes, mulas, caballos y hasta 
burros (4.911). Sin embargo, ya se registraba mayor número de arados de fierro (861, mientras que en 1930 hubo solo 129) y en los predios privados, un ligero aumento de tractores (de 5 registrados en 1930 a 15 en 1950) y camiones (de 5 a 12 en los mismos años). El número de carretas también aumentó de 70 en 1930 a 110 en $1950^{24}$. No sabemos qué uso se le daba a las carretas, pero su número nos parece poco si se considera que el número de localidades en el municipio era alrededor de 300.

Además de las pequeñas presas y manantiales existentes con los que se daba de beber a los animales y se irrigaban algunos cultivos, para 1950 en el sector privado se registraron varias plantas de bombeo $(120)^{25}$, lo que nos habla de cierta intensificación de la agricultura y la introducción de cultivos de riego como la alfalfa, la vid y el chile, cuyas cifras eran poco significativas veinte años antes. Ligada a la producción agrícola, la cría de ganado mayor, menor y las aves de corral seguían siendo fundamentales.

Así pues, aunque con variantes cuantitativas, la producción era muy similar a la de los años treinta y la de principios de siglo. Los cambios más importantes se refieren a la presencia de tractores y pozos profundos para irrigación, factores que anuncian la modernización agrícola y la entrada de cultivos más redituables en el mercado (chile, vid y alfalfa), pero que aún no cuestionaban la base fundamental de la hacienda agroganadera: la producción mayoritaria de maíz, frijol y trigo, realizados con la yunta y ligados a la cría de ganado.

Otros cambios se refieren al personal de trabajo. De 1930 a 1950 se observa la disminución de administradores: de 428 a 202, posiblemente tiene que ver con la inestabilidad que se vivía en los años treinta en la que muchos dueños de las fincas se fueron a vivir a Querétaro o a la ciudad de México; en contraste con el aumento de "renteros" o arrendatarios (26 registrados en 1930 y 92 en 1950), aparceros (de 12 en 1930 a 3.225 en 1950), cifra superior a la de los peones (2.587 en 1950). De estos, alrededor del 10\% se trataba de jóvenes menores de 16 años y mujeres ${ }^{26}$.

Según la información anterior y las entrevistas realizadas, para ese entonces la aparcería estaba muy generalizada. Si bien persistían las tierras de riego y de producción directa apoyada por peones, las tierras de temporal eran cultivadas por los medieros o tercieros que trabajaban "una yunta" (unidad de medida) con la yunta (instrumento) el maíz intercalado con frijol; se realizaba el cambio de parcela cada año, dejando la anterior en "descanso" y para el pastoreo del ganado mayor que, en muchas fincas, era igual o más importante que la agricultura.

El sistema de trabajo "a partido" mostraba sus bondades para el dueño de los recursos. La producción se veía dividida en tres partes: tierras, semillas e instrumental de trabajo (arado), y mano de obra. La cosecha era repartida según el aporte en estos renglones. Además, el patrón cobraba con faenas (días de trabajo gratuito) por el "derecho de piso" (lugar donde estaba la vivienda del trabajador y su familia) y por el "derecho de pasto". Al final del ciclo agrícola se repartía la cosecha y los esquilmos eran para el dueño de la tierra, quien también lo era del ganado.

Había otras ventajas de este tipo de organización: 1) la disponibilidad de contar con mano de obra para las siembras de producción directa, así como "abrir" tierras al cultivo, amansar toros y realizar otras labores que se requirieran; y 2) manejar las presiones del aumento de la producción con los términos de la aparcería. En los años cincuenta, por ejemplo, muchos finqueros prohibieron a sus trabajadores tener animales (bueyes o mulas que jalaban la yunta), para quedarse con un producto mayor de las cosechas. Pero quizá el principal mérito radica en el papel estabilizador de esta célula productiva en los tiempos de mayor incertidumbre social: la Revolución y los movimientos sociales de 19261940. Si no se hubieran manejado concesiones en los diferentes rubros de la aparcería, la producción hubiera caído todavía más, hubieran sido mayores las hambrunas y habrían sido más débiles los vínculos patrón-trabajador (Cfr. Sepúlveda, 2011: 114-120).

A pesar de los aumentos salariales decretados por los gobernadores de Guanajuato y seguramente implementados por las autoridades federales a nivel nacional, los trabajadores rurales seguían en la pobreza, en parte porque estos aumentos no siempre se ejercían, pero, también, por la poca e incierta producción obtenida, la que seguían compartiendo con la Iglesia por el diezmo. Además, si bien se habla del mediero y del peón, en realidad se trataba de sus unidades familiares, ya que la esposa y sus hijos frecuentemente participaban en las tareas productivas, sobre todo en la siembra y en la cosecha.

Por otra parte, el mercado de la tierra se daba en fracciones "medianas" o ranchos completos, 
pero no en parcelas de 5 o 6 ha que rompieran la racionalidad económica de la finca, por lo que la única posibilidad para un mediero o un peón de obtener una parcela estaba en los ejidos y algunos recurrieron a ese mercado, en ese entonces ilegal.

Así, si los ranchos y haciendas restablecieron su estabilidad extendiendo el sistema del trabajo "a partido" y manteniendo una organización jerarquizada; los ejidos también absorbieron esos estilos, y se alejaron cada vez más del ideal de constituir células participativas en la toma de decisiones y donde el usufructo de los recursos debía ser más o menos equitativo entre sus integrantes. Por eso he denominado a los ejidos de Dolores Hidalgo, en esta etapa de su historia (1940-1960), como "ejidos rancheros", ya que la base de su producción también se dio por la aparcería y la subordinación de los trabajadores agrícolas a los ejidatarios, al Comisariado Ejidal y/o al agente bancario.

\section{La organización productiva en los ejidos}

Entre 1950 y 1952 había 23 ejidos formalmente ejecutados (22 dotaciones y una ampliación) y los ejidatarios sumaban alrededor de 766 (jefes de familias) en todo el municipio. Pero si excluimos a los registrados en los ejidos "blancos" y "fantasmas"27, en realidad había 18 ejidos (más una ampliación) y 650 ejidatarios, que representaban alrededor de $40 \%$ de los beneficiados por las resoluciones presidenciales (Cfr. Sepúlveda, 2011:124).

En cuanto a la organización ejidal, la normatividad señalaba (y señala) a la asamblea general como máxima autoridad. En ella se nombra al Comisariado Ejidal (CE), constituido por: Presidente, Secretario y Tesorero, titulares y suplentes y al Comité de Vigilancia (CV), cuyos integrantes son: Presidente, Secretario y Vocal, titulares y suplentes. Pero en los años treinta, debido a las circunstancias en que se formaron los ejidos en el municipio, el mismo grupo de doce o de menos individuos, emparentados en unas cuantas familias, eran los integrantes de la asamblea y de la defensa rural.

En aquel entonces hubo dos personajes claves: 1) el Presidente del CE (PCE) que frecuentemente era quien había encabezado la solicitud de tierras, alfabetizado, poseía el "don de la palabra" y se encargaba de las relaciones con los funcionarios del gobierno y con el Presidente de la República; y 2) el Jefe de la Defensa Rural que encabezaba al grupo armado para apoyar la acción gubernamental, defender a los ejidatarios y los bienes otorgados, y entablar relaciones con el Ejército Federal. Además, los agraristas estaban en estrecha relación con las autoridades municipales y los representantes del gobierno estatal y federal.

En los años cincuenta la relación de los ejidatarios era con el Departamento de Asuntos Agrarios y Colonización (DAAC), el Banco Nacional de Crédito Ejidal (si aceptaban créditos), la Liga de Comunidades Agrarias y Sindicatos Campesinos por medio del Comité Regional Campesino (CRC) de la Confederación Nacional Campesina (CNC), y el Presidente de la República, pero ya no eran parte de las Reservas del Ejército, ni apoyaban a los funcionarios del gobierno federal, aunque tenían representantes (síndico y regidor, integrantes del CRC) en las autoridades municipales.

Por otra parte, en los ejidos se reflejaban las ineficiencias administrativas del aparato institucional, entre otras cosas, en la falta de delimitación de los ejidos, por tanto era causa de constantes problemas con el vecindario; y en la elaboración y entrega de los certificados de derechos agrarios: la certidumbre sobre la parcela ejidal dependía de haberse registrado en el censo y en mantener una buena relación con el representante ejidal y el funcionario bancario.

El presidente del Comisariado Ejidal y el Inspector de Campo del Banco resultaron personajes claves en la organización de los ejidos que tenían crédito, ya que, desde 1947, con "tonos de legalidad" procedieron a quitar u otorgar parcelas so pretexto de las deudas bancarias, derecho que solo correspondía al Presidente de la República. Con esta medida, en algunos ejidos se desplazó a los agraristas de los puestos de representación y se anuló (o pretendieron anular) a muchos campesinos que estaban en oposición al grupo de poder. En los ejidos que no tenían vínculos bancarios el arrebato de parcelas y la definición del ejidatario estuvieron, en parte, en manos del PCE, quien frecuentemente se prolongó por décadas en la representación (Cfr. Sepúlveda, 2011:124-129).

En los ejidos del municipio encontramos la presencia de algunos elementos comunes: la siembra de maíz y frijol realizada con la yunta; la cría de ganado mayor en pequeña escala; los abusos en la explotación de leña y madera, debido a su demanda para activar los hornos de alfareros y panaderos existentes en la cabecera municipal y su fácil convertibilidad en dinero; una población estratificada de ejidatarios por la concentración de 
recursos y el sistema de trabajo "a partido" muy extendido. En la producción agrícola el trabajo "a partido" se daba por el alquiler del instrumental de labranza (yunta) y/o por trabajar la superficie del ejido o laborar la parcela de un ejidatario específico; en la ganadería, también se daba este trato "a partido": alguien prestaba una vaca, el otro la alimentaba y cuidaba, se encargaba de la inseminación y, luego, se quedaba con el nuevo animal. En todos los ejidos en mayor o menor proporción se dieron estas formas de trabajo. También fue generalizado un enorme poder del presidente del comisariado ejidal y la inexistencia de la asamblea general de ejidatarios. Solo en casos extremos, los inconformes (ejidatarios o no) denunciaban las injusticias ante el Comité Regional Campesino y/o el Departamento Agrario.

Por estos rasgos generales del tipo de producción y de organización del trabajo, que no eran tan distintos de los que se realizaban en las fincas privadas, he caracterizado a estas unidades productivas como ejidos "rancheros", pues todo parece indicar que absorbieron los estilos productivos y de explotación heredados de la antigua hacienda.

En efecto, en el reparto de tierras del cardenismo, en teoría, el ejidatario estaría integrado en una célula democrática y participativa, donde la autoridad máxima era la asamblea general y donde se sustituía la tutela del terrateniente por la del Estado y el productor podía ofrecer sus excedentes al mercado. Pero el objetivo no se logró. Para los inicios de los años cincuenta en Dolores Hidalgo había diversos tipos de unidades ejidales (Cfr. Sepúlveda, 2011: 118-142):

- los blancos ofantasmas, que estaban dirigidos por los dueños de las tierras afectadas, el PCE era el mayordomo de la finca y el ejidatario no sabía de su estatus;

- los rancheros organizados por el PCE (frecuentemente exagrarista) quien se sintió dueño $\mathrm{y}$ administrador de los recursos, ignoraba a la oposición y a la asamblea que, en realidad, no existía; y

- los sinarquizados, que fueron ejecutados parcialmente con los trabajadores de las fincas afectadas como una forma de frenar la expansión de los agraristas.

Salvo los ejidos sinarquizados, cuyos ejidatarios trabajaban directamente las tierras, el trabajo en los otros ejidos se basó en la aparcería: el trabajador persistía dándole una parte al patrón, ignorando su estatus de ejidatario (en los blancos), o a los ejidatarios (en los rancheros).

Por otra parte, en pocos ejidos se logró un sentido de comunidad, quizá los que estuvieron más cerca de obtenerlo fueron los ejidatarios blancos y los sinarquizados, quienes, liderados por su patrón, defendieron las tierras para que no se las apropiaran los agraristas a quienes veían como abusivos y ajenos a la "gran familia de la finca".

De los ejidos rancheros podemos identificar aquellos controlados por el PCE, que manejaba el conjunto de los recursos y de los productores (Haciendita, Rioyos, El Tajo, San José de Badillo, entre otros), de otros que por su extensión constituían un mosaico de fracciones de ejidatarios y de renteros que trabajaban con su propia gente y que en algunos casos controlaban al PCE (Dolores, El Llanito, por ejemplo) y en otros no (Trinidad y Cantera, Tierra Blanca, Joconoxtlito del Llanito).

Estos ejidos rancheros constituyeron un espacio muy dinámico de relaciones mercantiles fuera de toda normatividad. Por ejemplo, la mayoría de los ejidatarios (en ese tiempo llamados nylon o aparceristas) no eran trabajadores del campo sin capital (como lo marcaba la normatividad), sino un sector "medio" ligado al comercio, a la ganadería, a los puestos públicos o políticos; la renta del territorio ejidal y la venta de derechos ejidales tampoco eran legales, pero se practicaban porque al finquero no le interesaba la venta de "pequeñas" superficies de tierras y hacer del trabajador un pequeño propietario: la promesa otorgada en los años más intensos del agrarismo, simplemente había quedado en el olvido $^{28}$. Durante el período del presidente López Mateos, en que el Departamento Agrario realizó la regularización en algunos de los ejidos, más de la tercera parte de los confirmados como ejidatarios habían comprado sus derechos ejidales pagando las deudas bancarias que dejaron otros, vendiendo sus animales para comprar su parcela al PCE, o habiendo sido aparceros por años de algún ejidatario (Sepúlveda, 2011:132). Asimismo, hubo sectores de aparceros que jamás fueron ejidatarios como fue el caso de los trabajadores de la finca Ojo de Agua de Cervantes que fueron medieros de los ejidatarios de Trinidad y Cantera por casi cuarenta años, sin que ninguna autoridad regulara esa anomalía.

La ilegalidad, en muchos casos ligada a la injusticia, y la centralización extrema del poder en los ejidos por la figura del PCE se arreglaba con propinas, bebidas en las cantinas, o la violencia. 
Los ejidos parecían contribuir a un fin político más amplio: sujetar a un sector de la población y tenerlo como base incondicional del Estado cuyo régimen, con imagen plurisectorial, pactaba cada vez más con el capital, relegaba a los trabajadores y creaba una masa de pobres y desempleados que se encaminaban a las ciudades y a los EUA.

Por otra parte, la evasión a la normatividad y la corrupción no eran exclusivas del sector ejidal, también se dieron en las fincas privadas, sobre todo si tenían la sombra de una acción agraria, solo que entonces el terrateniente entraba en complicidad con los representantes de las organizaciones políticas o con las autoridades del gobierno de la entidad o de la federación.

Así, las políticas de gobierno posteriores al reparto cardenista fueron opuestos al ideal del beneficio de las mayorías y en un sector de la población dieron como resultado una "cultura de amiguismo y compadrazgo político" inmersa en la complicidad y en la corrupción. La idea de democracia social se había perdido, y en su lugar la estructura jerárquica, mayoritariamente masculina, que alguna vez se observó en la hacienda y en la organización clerical, ahora era patente en los ejidos, en las organizaciones políticas y en las instancias de gobierno, y frecuentemente fue de la mano con la evasión de la normatividad.

Que los ejidos adoptaran estas formas de organización, en parte se debió al consentimiento de las autoridades agrarias, pero también a que los trabajadores del campo, en su mayoría, siguieron rechazando al ejido toda vez que veían en este un tipo de organización contraria a sus intereses e ideas religiosas que les traería maleficios. Sin embargo, no todos los trabajadores agrícolas eran opuestos al proyecto ejidal: había un sector que sí quería las tierras, que estaban inmersos en alguna acción agraria y que por ese motivo no conseguían empleo en las fincas del municipio; a ellos, los ejidatarios también los empleaban como aparceros, utilizando un discurso demagógico de "solidaridad de clase" en tanto se resolvieran sus demandas. Por ello el ejidatario muy pronto se convirtió en un explotador más del trabajador sin tierra.

Antes de terminar, y regresando a las figuras de organización de tipo jerárquico, quisiera señalar un aspecto más de la organización política del sector ejidal en el municipio: el liderazgo de corte caciquil establecido tanto en los ejidos con la figura del PCE como a nivel del Comité Regional Campesino por medio de sus representantes. En ambos niveles de organización que surgieron durante el reparto agrario, pero que se consolidaron en la contrarreforma, se ofrece una pequeña muestra de lo que fue parte de la organización política del Estado en aquellos años.

En los años sesenta la carrera hacia la democracia económica y política volvió a tomar fuerzas. En política agraria se trató de encauzar a los ejidos en la normatividad, combatir el cacicazgo e impulsar la demanda de tierras. En el municipio de estudio, la $\mathrm{CNC}$ perdió la vanguardia en el nuevo movimiento y la inconformidad social fue capitalizada por la Unión General de Obreros y Campesinos de México, más crítica y exigente con las políticas del Estado. A pesar de los conflictos, durante 1965 a 1980 la reforma agraria fue nuevamente considerada pieza clave de un cambio que no perdía de vista el impulso a la modernización y a la capitalización del campo.

\section{Comentarios y reflexiones generales}

En este trabajo he tratado de esbozar lo que a primera vista parecerían "cambios para no cambiar" en la sociedad de Dolores Hidalgo durante los primeros 60 años del siglo XX. Y de esas líneas quiero polemizar en dos aspectos: 1) algo que se plantearon los líderes de la Revolución en Guanajuato: la población de trabajadores de las haciendas eran proletarios y, por tanto, las medidas reivindicativas entraban en el ámbito laboral, o campesinos como lo pensaron los agraristas de los años treinta. Si fueron campesinos, ¿cuáles fueron los aspectos que perduraron? (hasta los años sesenta) y, ligado a lo anterior, 2) ¿qué es lo que verdaderamente se puede señalar como tradicional? y ¿qué elementos constituyen formas de producción en transición?

En la primera cuestión habría que recordar la amplia gama de trabajadores en las haciendas: no era lo mismo los ayudantes en la administración de las explotaciones de las fincas (mayordomos y rayadores, por ejemplo) que los productores directos de granos y ganado. Los finqueros sinarquistas pudieron identificar bien a los sectores de trabajadores, y para minimizar los efectos del reparto agrario a algunos les aumentaron el salario (reivindicación laboral) y a otros les ofrecieron una aparcería ventajosa que, en teoría, les ayudaría a pagar la parcela (reivindicación agraria), con la que podría pensarse que se acentuaba la campesinización del trabajador.

Pero quizá lo más importante es saber qué quería el trabajador de las fincas, y me atrevo a decir que 
quería la tierra y con esta tener el control del proceso productivo que le facilitara la vida. En mi opinión, el aparcero no aceptó la oferta del gobierno porque no entendió qué era el ejido, no imaginaba qué era ser "aparcero del gobierno" ni por qué tenía que ser anticlerical y pasar a ser soldado del Ejército Federal. Prefirió ser fiel a su patrón, incluso ser su soldado y confiar en él, ya que en teoría también le daría la tierra sin traicionar sus principios religiosos. Algunos finqueros sí dieron las tierras en propiedad, otros la otorgaron en los años sesenta con el renacimiento del agrarismo gubernamental, y otros más nunca cumplieron sus palabras.

Un hecho que respalda la afirmación de que el trabajador quería la tierra es que durante los años sesenta y setenta la nueva generación de finqueros decidió sumarse a la modernización (con irrigación, maquinaria y cultivos más redituables en el mercado) y romper con el pacto social de la aparcería; buena parte de los hijos de los cristeros se sumó a la opción del ejido y luchó por la tierra con tanta fe como alguna vez sus padres defendieron a la hacienda.

En relación con la segunda cuestión, identificar cuáles fueron las formas productivas tradicionales y cuáles las transicionales, quiero señalar que la finca reconstruida de los años cuarenta y cincuenta fue la continuación de la tradición de la hacienda; y las modalidades de los ejidos en cuya base estaba el trabajo de los aparceros (que fue en la mayoría) también corresponden a la continuidad de las tradiciones de la hacienda. Por eso califiqué a los ejidos como rancheros, para expresar un sincretismo de formas teóricamente antagónicas: la hacienda y el ejido, aunque en este sincretismo se intensificaron dinámicas de tipo mercantil, producto de la ilegalidad y la corrupción. Sin embargo, hay que señalar que la corrupción también fue un mecanismo que permitió la reconstrucción de la hacienda.

Los ejidos de aquel tiempo (1940-1960) también fueron formas transicionales que tenían dos vías de desarrollo: reestructurarse según la normatividad, o afianzarse en la línea donde la tierra tenía un valor de cambio y donde, de hecho, ya había entrado al mercado. La primera opción fue la estimulada por el gobierno y pretendió afianzarse en los siguientes 20 años convirtiendo a los ejidos en células productivas ligadas a la inversión estatal; y la segunda se ha dado a partir de la decadencia del modelo anterior, la sobrepoblación, las sequías, la emigración y las nuevas reglas del juego que han impuesto las políticas neoliberales.

Otros aspectos que considero tradicionales en la organización de los dolorenses (y guanajuatenses) es la persistencia de las "ligas con el terruño" o identidad local, la importancia de las redes del parentesco y la religiosidad católica por lo menos en su discurso, aunque no siempre en su práctica moral. Es decir, me sumo a lo señalado por Guillermo De la Peña (1993:164), quien considera que entre los rancheros del centro y norte de México los valores locales no se manifiestan en un complejo ceremonial comunitario ni en la defensa de patrimonios territoriales, pero sí en la apreciación de una vasta red de parentesco y alianzas interfamiliares.

\section{Referencias Citadas}

De la Peña, Guillermo

1993 Los desafíos de la clase incómoda: el campesinado frente a la antropología americanista", en: León Portilla, Miguel (coord.) Motivos de la antropología americanista. Indagaciones en la diferencia, México, Fondo de Cultura Económica, pp. 134-166.

Moreno, Manuel

1977 Historia de la Revolución en Guanajuato, México, Instituto Nacional de Estudios Históricos de la Revolución Mexicana.

Sepúlveda Garza, Manola

2011 Vaivenes de la historia ejidal. Dolores Hidalgo, CIN, Guanajuato, 1900-1970, México, Escuela Nacional de Antropología e Historia/ Instituto Nacional de Antropología e Historia.

Serrano A., Pablo

1992 La batalla del espíritu. El movimiento sinarquista en el Bajio (1932-1951), Tomos I y II, México, Consejo Nacional para la Cultura y las Artes.

\section{Fuentes}

Censo General de la República Mexicana, 28 de octubre de 1900. Estado de Guanajuato, México, Dirección General de Estadística/ Secretaría de Fomento, Colonización e Industria.

Censo y División Territorial del Estado de Guanajuato, 1900. I Censo Ejidal del Estado de Guanajuato, Vol. II, 1935.

V Censo General de Población del Estado de Guanajuato, 1930.

VII Censo General de Población y vivienda del Estado de Guanajuato, 1950.

III Censo Agrícola, Ganadero y Ejidal del estado de Guanajuato, 1950, México, Secretaría de Economía Nacional / Dirección General de Estadística, 1956.

Archivo del Registro Agrario Nacional, Guanajuato.

Diversas estancias de campo realizadas entre 1998 y 2006. 
Notas

1 Trabajo a partido significa que el trabajador tomaba solo una parte de la cosecha. El proceso productivo se dividía en: tierra, yunta y semilla, y mano de obra. Si el dueño de la finca daba la tierra, la yunta y la semilla, y el trabajador solo colocaba la mano de obra, entonces la producción le correspondía en $2 / 3$ partes al finquero y $1 / 3$ al trabajador.

2 Se usa como sinónimo de trabajo a "partido".

3 Censo General de la República Mexicana, 28 de octubre de 1900. Estado de Guanajuato, México, Dirección General de Estadística/ Secretaría de Fomento, Colonización e Industria.

4 20/04/1973. Informe Reglamentario, Ojo de Agua de Tapextle, exp. 3498; Pilar Sánchez (N.1916), El Pueblito, 2005.

5 Informe Reglamentario de San Gabriel. Exp. San Gabriel, ampliación 3203.

6 Censo General de la República Mexicana, 28 de octubre de 1900. Estado de Guanajuato, México, Dirección General de Estadística/ Secretaría de Fomento, Colonización e Industria.

7 Censo General de la República Mexicana, 28 de octubre de 1900. Estado de Guanajuato, México, Dirección General de Estadística/ Secretaría de Fomento, Colonización e Industria.

8 Censo y División Territorial del Estado de Guanajuato, 1900.

$9 \quad$ En estas tierras, el agua para los sembradíos se obtiene de las lluvias, y lo de primera y segunda se refiere a lo pedregoso y/o a la profundidad del suelo.

10 Antonio Vargas (N. 1936), San Antonio del Gallinero, 2002.

11 J. Manuel González Azanza, Trancas, 1998.

12 Casimiro Peña (N. 1918), dueño de la Hacienda La California, 1997.

13 Cuarterón es una medida tradicional equivalente a $1,5 \mathrm{~kg}$.

14 Diversas entrevistas en la antigua exhacienda de La Venta, Terreros (fracción 3 de La Venta) y en San Gabriel.

15 Diversas entrevistas en la antigua exhacienda de La Venta, Terreros (fracción 3 de La Venta) y en San Gabriel.

16 Victoriano Valencia (N. 1918), ejidatario de Jesús María, 2001; Antonio Vargas (N. 1936), San Antonio de El Gallinero, 2002.

17 Pablo A. de la Garza (1914) se proponía aumentar el salario de los peones a $\$ 0,75$ y reducir la jornada laboral a 9 horas; Abel Serrato señalaba además dar el descanso dominical y cancelar actividades durante las fiestas nacionales, los días santos, el 25 de diciembre y el 1 de enero; Siurob Ramírez (1915-1916) emitió un decreto en que se obligaba a los dueños de las haciendas establecer escuelas, fijó la jornada en 8 horas, reglamentó el descanso dominical y estableció bases para el pago de los accidentes del trabajo y la protección del trabajo de mujeres y niños. Cfr. Moreno, Manuel, 1977, Historia de la Revolución en Guanajuato, México, Instituto Nacional de Estudios Históricos de la Revolución Mexicana, pp. 126-161.

18 Con el término sinarquista se quería decir con gobierno, autoridad y disciplina. El sinarquismo fue un movimiento popular de la derecha católica que se opuso abiertamente a las reformas gubernamentales del cardenismo, representó uno de los movimientos más importantes de la posrevolución y abarcó el centro-oeste del país. Se autonombró defensor de la libertad religiosa, de la familia y de la propiedad privada, en contra de la educación socialista, la reforma agraria y de otros proyectos pensados como "comunistas".

19 La mediería y la renta de la tierra existió desde la época de la Colonia, pero durante el porfiriato la mediería se había relegado a las tareas más pesadas y se intensificó el trabajo de los peones.

20 VII Censo General de Población y vivienda del Estado de Guanajuato, 1950.

21 VII Censo General de Población y vivienda del Estado de Guanajuato, 1950.

22 III Censo Agrícola, Ganadero y Ejidal del estado de Guanajuato, 1950, México, Secretaría de Economía Nacional / Dirección General de Estadística, 1956.

23 III Censo Agrícola, Ganadero y Ejidal del estado de Guanajuato, 1950, México, Secretaría de Economía Nacional / Dirección General de Estadística, 1956.

24 Datos comparativos del I Censo ejidal del estado de Guanajuato, 1935 y el III Censo Agrícola, Ganadero y Ejidal del estado de Guanajuato, 1950, México, Secretaría de Economía Nacional / Dirección General de Estadística, 1956.

25 III Censo Agrícola, Ganadero y Ejidal del estado de Guanajuato, 1950, México, Secretaría de Economía Nacional / Dirección General de Estadística, 1956.

26 III Censo Agrícola, Ganadero y Ejidal del estado de Guanajuato, 1950, México, Secretaría de Economía Nacional / Dirección General de Estadística, 1956.

27 Se considera "ejidos blancos" o "ejidos fantasma" aquellos organizados por el dueño de la finca, quien enviaba el listado de beneficiarios a las oficinas del Departamento Agrario y también definía la superficie que se trabajaba. El campesino con estatus de ejidatario no estaba enterado de serlo.

28 De acuerdo con Serrano (1992:TII 257-260), hubo un cambio en la propuesta de los sinarquistas: insistieron en dar la tierra en forma de pequeñas propiedades, pero no en sus tierras, sino en las zonas que el gobierno se planteara colonizar 
